\title{
ENSINO DE CIÊNCIAS E EDUCAÇÃO AMBIENTAL NO NÍVEL FUNDAMENTAL: ANÁLISE DE ALGUMAS ESTRATÉGIAS DIDÁTICAS
}

\author{
Science teaching and enviromental education in the \\ Secondary School: an analysis of some didactical strategies
}

\author{
Ana Lucia Gomes Cavalcanti Neto ${ }^{1}$ \\ Edenia Maria Ribeiro do Amaral ${ }^{2}$
}

\begin{abstract}
Resumo: Esse trabalho tem como objetivo analisar estratégias didáticas utilizadas por professoras de Ciências para o desenvolvimento de temas ambientais nas turmas de $5^{\mathrm{a}}$ e $6^{\mathrm{a}}$ séries do Ensino Fundamental II, de três escolas públicas do Município da Escada (PE); e avaliar se e/ou como tais estratégias contribuem para a implantação de uma proposta de Educação Ambiental Crítica nesse nível de ensino. Para análise da dinâmica discursiva das salas de aula observadas, utilizamos aspectos da estrutura analítica para o discurso da sala de aula de ciências proposta por Mortimer e Scott (2002). Os dados apontam que estratégias didáticas podem constituir elementos fundamentais para o desenvolvimento da EA Crítica, quando contribuem para que o processo educativo não se resuma ao uso do livro; valorizam o diálogo entre saberes em uma dinâmica interativa, e, ainda, apontam para a necessidade da inclusão dos princípios norteadores da EA Crítica na formação continuada de professores.

Palavras-chave: Educação ambiental crítica. Estratégias didáticas e ensino de ciências.
\end{abstract}

\begin{abstract}
This work aims to analyze teaching strategies adopted by science teachers in order to deal with environmental themes in three secondary public schools, involving students of years 5 and 6 , in Escada (PE), Brazil; and to evaluate how specific strategies can contribute to the inclusion of Critical Environmental Education at that level of instruction. Data were analyzed taking into account an analytical framework for discursive dynamics in science classrooms proposed by Mortimer and Scott (2002). Results pointed out that some didactical strategies can be considered as fundamental to developing Critical Environmental Education in the classroom, since they contribute to changing instruction, which is normally supported just by the textbook. Beyond this they can launch dialogic. approaches to the content starting from an interactive process of discussion in the classroom. Analysis also pointed out a necessary redefinition of programs for science teacher's professional development focused on Critical Environmental Education principles.
\end{abstract}

Keywords: Critical environmental education. Didactical strategies and science teaching.

\footnotetext{
${ }^{1}$ Licenciatura em Ciências Biológicas, mestre em Ensino das Ciências. Professora da Educação Básica. Escada, PE, Brasil.<analuneto@gmail.com>

${ }^{2}$ Engenharia Química, doutora em Educação. Docente, Programa de Pós-Graduação em Ensino das Ciências, Universidade Federal Rural de Pernambuco. Recife, PE, Brasil. <edsamaral@uol.com.br>

${ }^{1}$ Rua Flora dos Santos Silveira, 190

Mangueira - Escada, PE

$55.500-000$ 


\section{Introdução}

Neste trabalho será apresentada uma análise de estratégias didáticas utilizadas por professores de Ciências para o desenvolvimento de temas ambientais em aulas de Ciências e de Educação Ambiental, nas turmas de $5^{\mathrm{a}}$ e $6^{\mathrm{a}}$ séries do Ensino Fundamental II, de três escolas públicas do Município da Escada (PE). Na análise, avaliamos se e/ou como tais estratégias contribuem para a implantação de uma proposta de Educação Ambiental Crítica, nesse nível de ensino.

A partir desse propósito, consideramos importante refletir sobre a questão ambiental que emerge no momento atual, e que apresenta grandes desafios à sobrevivência da espécie humana e da vida no planeta. Há um grande debate em diferentes instâncias - científica, econômica, social e política - no qual se coloca que a sustentabilidade do nosso planeta Terra está ameaçada, haja vista a perda de um equilíbrio ambiental, isso acompanhado de sistemas que promovem desigualdades sociais, culturais, injustiça social, econômica e violência. Segundo Morin (2003), é uma crise de valores e de percepção, que tem suas raízes nos modos pelos quais grupos sociais pensaram e construíram suas relações com a natureza. Segundo Carvalho (2006), em um dado momento, a natureza é percebida como o domínio do selvagem pela cultura e, em outro, como a reserva do bom e do belo, e isso resultou numa percepção de ambiente como fenômeno estritamente biológico, no qual as interações ecossistêmicas seguem de maneira autônoma e independente da interação com o mundo cultural humano.

Diante da complexidade dos problemas sociais e ambientais que ora vivenciamos e da necessidade da construção de uma sociedade mais justa, solidária e humana, torna-se importante superar essa percepção, ampliando-se concepções sobre o ambiente, de uma dimensão estritamente biológica para uma concepção que inclui as dimensões sociais e culturais, o mundo das humanidades. Nesse sentido, trata-se de construir um novo ideário ambiental que nos possibilite uma nova visão sobre o ambiente e as suas relações com o mundo social. Carvalho (2006) propõe a construção de uma visão socioambiental, uma vez que se orienta por uma racionalidade complexa e interdisciplinar e apresenta uma visão sobre o ambiente natural como um campo de interações entre a cultura, a sociedade e a base física/biológica dos processos vitais, no qual todos os elementos dessa relação se modificam dinâmica e mutuamente.

Nesse processo de mudança de concepções, o processo educativo torna-se fator essencial, constituindo-se, predominantemente, a partir de experiências educativas que facilitem a percepção integrada do ambiente, percepção de que ser humano é natureza, e não apenas parte dela. De acordo com Guimarães (2005), ao assimilar essa visão (holística), a dominação do ser sobre o ambiente perde o seu valor, podendo resultar em atitudes harmoniosas tanto individuais como coletivas, por parte do ser humano, que possibilitarão, segundo Dias (1999), uma "ação mais racional e capaz de responder às necessidades sociais" (p. 107).

O processo educativo, nesse contexto, deve ser planejado e vivenciado no sentido de possibilitar, aos indivíduos, uma compreensão, sensibilização e ação que resulte na formação de uma consciência da intervenção humana sobre o ambiente, que seja ecologicamente equilibrada. Para isso, espera-se que o mesmo seja conduzido no sentido de possibilitar a formação de um pensamento crítico, criativo e conectado com a necessidade de propor respostas para o futuro, capaz de analisar as complexas relações entre os processos naturais e sociais e de atuar no ambiente em uma perspectiva global, respeitando as diversidades socioculturais. Isso re- 
quer um pensamento crítico com relação à Educação Ambiental e, portanto, a definição de um posicionamento ético-político, "situando o ambiente conceitual e político onde a educação ambiental pode buscar sua fundamentação enquanto projeto educativo que pretende transformar a sociedade" (CARVALHO, 2006, p. 158).

Nesse cenário, uma proposta de Educação Ambiental Crítica se destaca como possibilidade de construção desse novo pensar, por tratar-se, de acordo com Carvalho (2006), de uma proposta educativa que se destina à formação de valores e atitudes necessários a uma nova postura frente às questões ambientais, por meio de um processo educativo emancipatório. Para Loureiro (2006, p. 32):

A ação emancipatória é o meio reflexivo, crítico e autocrítico contínuo, pelo qual podemos romper com a barbárie do padrão vigente de sociedade e de civilização, em um processo que parte do contexto societário em que nos movimentamos do "lugar" ocupado pelo sujeito, estabelecendo experiências formativas em que a reflexão problematizadora da totalidade, apoiada numa ação consciente e política, propicia a construção de sua dinâmica.

O autor alerta para o ato de emancipar, não como um estabelecimento do caminho único para a salvação, mas como uma possibilidade de construção de caminhos que julgamos mais adequados à vida social e planetária, diante da compreensão que temos destes em cada cultura e forma de organização societária, produzindo patamares diferenciados de existência.

Portanto, para se promover uma educação cidadã, que possibilite uma mudança social libertadora, como também a formação de cidadãos e cidadãs com capacidade para participarem da tomada fundamentada de decisões e que sejam comprometidos com as questões ambientais, faz-se necessária uma nova proposta educativa, centrada: na conscientização, mudança de atitude e práticas sociais, desenvolvimento de conhecimentos, capacidade de avaliação e participação dos educandos. É essa perspectiva de Educação Ambiental que orienta a análise das estratégias didáticas adotadas pelas professoras nesta pesquisa.

A proposta de Educação Ambiental Crítica guarda relações com algumas perspectivas que emergem na área da educação científica. Essas relações tornam-se importantes considerando que, muitas vezes, a Educação Ambiental, nas escolas, é incorporada ao ensino das ciências e de geografia. Com relação ao ensino de ciências, Cachapuz; Praia; Jorge (2002) considera que importa possibilitar, ao aluno, a condição de cidadão ativo, que tem de desempenhar papéis e partilhar responsabilidades para mudar o atual quadro de crise ambiental. Para isso, é necessário que, mais do que informação e conceitos, a escola se proponha a trabalhar com atitudes, com formação de valores, como nos assinalam os Parâmetros Curriculares Nacionais, PCN (BRASIL, 1998a), e nas novas orientações para o Ensino de Ciências (BRASIL, 2004).

Carvalho (2006) afirma que a formação do indivíduo só faz sentido se pensada em relação com o mundo em que ele vive e pelo qual é responsável. Para atender uma concepção de Ensino de Ciências Naturais como a proposta, de acordo com Carvalho (2004, p. 3), "é preciso conjugar harmoniosamente a dimensão conceitual da aprendizagem disciplinar com a dimensão formativa e cultural". Portanto, nessa concepção, o conteúdo curricular de Ciências ganha duas novas dimensões, além da dimensão conceitual, a procedimental e a atitudinal. 
Direcionar o conteúdo de Ciências nessa perspectiva, como afirma a autora, é direcionar o ensino para uma finalidade cultural mais ampla, no sentido de possibilitar, ao indivíduo, a condição de tomar decisões fundamentadas e críticas. Nesse sentido, para este trabalho, consideramos a perspectiva de alfabetização científica, na qual alfabetizar cientificamente representa uma forma de pensar no homem como um cidadão que precisa compreender o mundo numa perspectiva também científica, para melhor interagir nele (CHASSOT, 2006). Acreditamos que o processo educativo voltado para questões ambientais, como colocado anteriormente, pode se concretizar a partir do ensino de Ciências na escola, visando construir uma compreensão do ambiente, tanto na dimensão científica como humana e social.

Pensar o Ensino de Ciências, a partir de uma proposta educativa ambiental, leva a pensar sobre o "como ensinar" e a refletir sobre como esse ensino pode impulsionar a formação de cidadãos conscientes, aptos a decidirem e atuarem na realidade socioambiental, de modo comprometido com a vida (BRASIL, 1998b). Nesse contexto, Haidt (1999) coloca que as estratégias didáticas ou procedimentos de ensino - como exposição oral pelo professor, leituras, questionamentos, exibição e análise de vídeos, investigação, apresentação e discussão de dados e apresentação oral pelos alunos, entre outras - destacam-se como uma forma de intervenção que contribui para o professor colocar o aluno em contato com fatos ou fenômenos que lhes possibilitem modificar sua conduta. Assim, o segredo do sucesso da aprendizagem que poderá possibilitar a mudança de condutas está, também, na seleção de estratégias que sejam adequadas aos objetivos propostos. Segundo Masetto (1997), a escolha de estratégias adequadas favorece uma série de situações educativas, como: dinamismo nas aulas, participação dos alunos, integração e coesão grupal, motivação e interesse dos educandos, atendimento às diferenças individuais, ampliação das experiências de aprendizagem, entre outras.

Nosso estudo toma como base o pressuposto de que há uma necessidade de se trabalhar a Educação Ambiental, numa perspectiva crítica, de forma mais sistemática em salas de aula, por meio de uma atuação pedagógica e ecológica sustentada nos princípios da criatividade e de práticas docentes emancipatórias, norteadas pelo empoderamento e pela justiça ambiental e social (JACOBI, 2005). Assim, construir uma postura docente na qual prevaleça a concepção de educação como um ato também voltado para a transformação social.

Diante do exposto, com o desejo de realizar e aprofundar estudos sobre possibilidades de uma efetiva inserção de elementos de Educação Ambiental Crítica em aulas de Ciências Naturais, neste trabalho, buscamos analisar estratégias didáticas que enfatizam a questão ambiental e que sejam desenvolvidas por professoras de Ciências, em aulas de Ciências e Educação Ambiental, identificando dificuldades e possibilidades apresentadas por esses professores no que diz respeito ao desenvolvimento de uma EAC no Ensino Fundamental II.

A opção por desenvolver a respectiva pesquisa está relacionada ao fato de se perceberem, na prática, lacunas entre a formação científica e a formação ambiental dos estudantes e, ao mesmo tempo, se vislumbrarem possibilidades de efetivação da Educação Ambiental Crítica nessa área de ensino. Tais perspectivas estão relacionadas a dois aspectos principais: o primeiro diz respeito ao fato da proximidade entre os fenômenos naturais - objeto de estudo da referida área - e as questões ambientais, haja vista ser objetivo, também, da Educação Ambiental, segundo Mergulhão (1998), entender e apreciar as inter-relações que os seres humanos estabelecem entre si, suas culturas e seus meios biofísicos. O segundo aspecto está relacionado às convergências existentes entre as atuais Orientações Curriculares para o ensino 
de Ciências a as propostas de Educação Ambiental, evidenciadas pelos Parâmetros Curriculares Nacionais por meio de temas transversais relacionados com o meio ambiente.

\section{Metodologia}

Este trabalho é parte de uma dissertação de mestrado, na qual adotamos uma abordagem qualitativa para a construção e análise dos dados, buscando realizar um estudo de natureza etnográfica. A intervenção no campo de pesquisa ocorreu no período de março a junho de 2008, e envolveu três professoras de Ciências do Ensino Fundamental II da rede municipal da cidade de Escada, Zona da Mata Sul de Pernambuco, ambas licenciadas em Biologia e denominadas aqui como P1, P2 e P3. Foram observadas aulas de Ciências de $5^{a}$ e $6^{a}$ série, respectivamente, para P1 e P2, e aulas de Educação Ambiental de 5a série, para P3, conforme descrito no Quadro 1. As aulas foram gravadas na íntegra em áudio e vídeo, mas somente algumas delas foram transcritas e analisadas (ver Quadro 1). Salientamos que, em trabalhos anteriores, apresentados no V EPEA - Encontro de Pesquisa em Educação Ambiental - foram analisadas concepções de ambiente das referidas professoras.

Quadro 1. Sistematização das aulas analisadas.

\begin{tabular}{|c|c|c|c|c|}
\hline Professora & $\begin{array}{c}\text { Número de aulas } \\
\text { observadas }\end{array}$ & \multicolumn{1}{|c|}{ Aulas analisadas } & $\begin{array}{c}\text { Tempo de } \\
\text { aula }\end{array}$ & $\begin{array}{c}\mathbf{N}^{\circ} \text { de episódios } \\
\text { analisados }\end{array}$ \\
\hline P1 & 11 aulas & $\begin{array}{l}\text { Aula } 1-1^{\text {a }} \text { e } 2^{\text {a }} \text { aula da sequência } \\
\text { (geminada) }\end{array}$ & 80 min. & 02 \\
\hline P2 & 06 aulas & $\begin{array}{l}\text { Aula } 2-3^{\text {a }} \text { e } 4^{\text {a }} \text { aula da sequência } \\
\text { (geminada) }\end{array}$ & 80 min. & 02 \\
\hline P3 & 06 aulas & $\begin{array}{l}\text { Aula } 3-1^{\text {a }} \text { aula da sequência } \\
\text { Aula } 4-3^{\mathrm{a}} \text { aula da sequência }\end{array}$ & 80 min. & 04 \\
\hline
\end{tabular}

Os episódios para análise foram escolhidos considerando o momento em que temas ambientais emergiam mais fortemente na sala de aula, de acordo com diferentes intenções das professoras nos respectivos momentos educativos. No caso da disciplina de Educação Ambiental, a escolha dos episódios foi feita a partir de pistas que sinalizavam possibilidades de efetivação da Educação Ambiental Crítica, uma vez que a disciplina tem como proposta o desenvolvimento de temáticas ambientais. A partir da análise desses episódios, foi possível, ainda, categorizar as concepções das referidas professoras sobre a visão de ambiente (naturalista ou socioambiental). Foram selecionados, para análise, dois episódios de P1, dois de P2 e quatro episódios de $\mathrm{P} 3$. Na análise, utilizamos aspectos da estrutura analítica para o discurso da sala de aula de Ciências proposta por Mortimer e Scott (2002). A estrutura utilizada compreende cinco aspectos inter-relacionados, que focalizam o papel do professor e são agrupados em termos de focos de ensino, abordagem e ações, conforme o Quadro 2. 
Quadro 2. Aspectos da estrutura de análise proposta por Mortimer e Scott (2002, p. 285).

\begin{tabular}{|l|l|}
\hline \multicolumn{2}{|c|}{ Aspectos da análise } \\
\hline I Focos de ensino & $\begin{array}{l}\text { 1 Intenções do professor } \\
\text { 2 Conteúdo }\end{array}$ \\
\hline II Abordagem & 3 Abordagem comunicativa \\
\hline III Ações & $\begin{array}{l}\text { 4 Padrões de interação } \\
\text { 5 Intervenções do professor }\end{array}$ \\
\hline
\end{tabular}

Nesta pesquisa, dos cinco aspectos que compõem a estrutura analítica proposta, utilizamos apenas quatro: intenções do professor, forma de abordagem do conteúdo, abordagem comunicativa e intervenções do professor. No que se referem às intenções do professor, os autores consideram que desenvolver a estória científica no plano social é foco central desse aspecto e sugerem que essas intenções não são constantes, elas podem variar durante uma sequência de aulas, podendo sofrer influências de aspectos diversos. São as seguintes as intenções sintetizadas por Mortimer e Scott (2002): Criar um problema; Explorar e/ou checar as ideias dos alunos; Introduzir ou desenvolver a estória científica; Guiar os alunos no trabalho com as ideias científicas e dar suporte ao processo de internalização; Guiar os alunos na aplicação das ideias científicas e na expansão do seu uso, transferindo progressivamente, para eles, o controle e a responsabilidade por esse uso; Manter a narrativa: sustentar o desenvolvimento da estória científica.

Com relação ao segundo aspecto, diferentemente do que é proposto por Mortimer e Scott, estruturamos a análise do conteúdo do discurso da sala de aula em termos de categorias apresentadas no Quadro 3, tomando por base a distinção entre conceitos, procedimentos e atitudes, normas e valores, para analisarmos as diferentes formas de abordagens aos temas ambientais. Salientamos que a abordagem do conteúdo utilizada tomou por base as orientações colocadas nos PCN (BRASIL, 1997), que caracterizam os conteúdos em conceitual, procedimental e atitudinal.

Quadro 3. Formas de abordagem ao conteúdo.

\begin{tabular}{|l|l|}
\hline Conceituais & $\begin{array}{l}\text { Referem-se à construção ativa das capacidades intelectuais para se operar com símbolos, } \\
\text { ideias, imagens e representações que permitem organizar a realidade. }\end{array}$ \\
\hline Procedimentais & $\begin{array}{l}\text { Expressam um saber fazer que envolve tomar decisões e realizar uma série de ações, de } \\
\text { forma ordenada e não aleatória, para se atingir uma meta. }\end{array}$ \\
\hline Atitudinais & $\begin{array}{l}\text { Relacionam-se às disposições para se avaliar uma ocorrência, situação, pessoa ou objeto e } \\
\text { para se atuar em concordância com essa avaliação. Envolve valores, normas e atitudes. } \\
\text { Seu aprendizado implica mudança de comportamento e estão relacionadas com valores de } \\
\text { quem ensina. }\end{array}$ \\
\hline
\end{tabular}


No que se refere ao terceiro aspecto da análise, a abordagem comunicativa, para Mortimer e Scott (2002), ela é central na estrutura analítica, uma vez que fornece a perspectiva de como o professor faz as intervenções pedagógicas ao trabalhar as intenções e o conteúdo do ensino. Nesse contexto, os autores consideram duas dimensões do discurso, dialógico ou de autoridade e interativo ou não interativo, a partir das quais caracterizam a comunicação entre professor e alunos em quatro abordagens: Interativa/dialógica - quando há a participação de mais de uma pessoa no discurso e vários pontos de vista são considerados pelo professor. O ponto de vista científico e o ponto de vista apresentado pelos estudantes; Interativa/de autoridade - quando há a participação de mais de uma pessoa no discurso, porém apenas um ponto de vista é considerado, geralmente, o ponto de vista científico. As perguntas, normalmente, são conduzidas pelo professor, no sentido de chegar ao ponto de vista considerado; Não-interativa/dialógica - quando há a participação de apenas uma pessoa no discurso, mas vários pontos de vista são considerados pelo professor, e Não-interativa/de autoridade - quando apenas uma pessoa participa do discurso e apenas um ponto de vista específico é considerado.

O quarto aspecto da nossa análise especifica as intervenções pedagógicas feitas pelo professor e baseia-se no esquema de Scott (1998 apud MORTIMER; SCOTT, 2002), no qual seis formas de intervenção pedagógica foram identificadas. Neste trabalho, utilizamos essas categorias, que se constituíram como elementos para a caracterização das estratégias didáticas utilizadas pelos professores em sala de aula. O Quadro 4 relaciona o foco e as ações do professor que caracterizam cada uma das seis formas de intervenção.

Para a organização e sistematização dos dados analisados, consideramos a etnografia interacional. O primeiro procedimento analítico utilizado, adaptado da etnografia interacional, foi a construção de mapas de atividades de todas as aulas observadas. Segundo Amaral e Mortimer (2007), tais mapas nos permitem uma visão global da sequência de aulas analisadas e nos possibilitam a escolha dos episódios.

Neste trabalho, na construção dos mapas, especificamos o tempo de cada atividade desenvolvida pelos sujeitos (coluna 1), a nominação de cada atividade (coluna 2), os temas desenvolvidos em sala de aula e as ações desenvolvidas pelos participantes do processo. A partir dos dados sobre as atividades desenvolvidas, foi possível fazer a escolha das aulas a serem analisadas e dos respectivos episódios. A terceira coluna é relativa ao conteúdo abordado pelas professoras no momento da pesquisa. Na quarta coluna estão especificadas ações realizadas pela professora e pelos alunos. Tais informações nos fornecem indícios da forma de abordagem comunicativa estabelecida durante as aulas, como, também, nos possibilita analisar as intervenções realizadas pelas professoras no processo ensino-aprendizagem. $\mathrm{Na}$ quinta e última coluna, apresentamos comentários gerais sobre a participação dos alunos. A disposição dos textos, ao longo das colunas, obedece a uma ordem cronológica dos fatos. 
Cavalcanti Neto, A. L. G.; Amaral, E. M. R.

Quadro 4. Intervenções do professor (Fonte: MORTIMER; SCOTT, 2002, p. 289).

\begin{tabular}{|c|c|c|}
\hline $\begin{array}{l}\text { Intervenções } \\
\text { do professor }\end{array}$ & Foco & Ação - o professor: \\
\hline $\begin{array}{l}1 \text { Dando forma } \\
\text { aos significados }\end{array}$ & Explorar as ideias dos estudantes. & $\begin{array}{l}\text { Introduz um termo novo; parafraseia uma } \\
\text { resposta do estudante; mostra a diferença entre } \\
\text { dois significados. }\end{array}$ \\
\hline $\begin{array}{l}2 \text { Selecionando } \\
\text { significados }\end{array}$ & \multirow[t]{2}{*}{$\begin{array}{l}\text { Trabalhar os significados no } \\
\text { desenvolvimento da estória científica }\end{array}$} & $\begin{array}{l}\text { Considera a resposta do estudante na sua fala; } \\
\text { ignora a resposta de um estudante. }\end{array}$ \\
\hline $\begin{array}{l}3 \text { Marcando } \\
\text { significados- } \\
\text { chave }\end{array}$ & & $\begin{array}{l}\text { Repete um enunciado; pede ao estudante que } \\
\text { repita um enunciado; estabelece uma sequência } \\
\text { I-R-A } \mathrm{A}^{3} \text { com um estudante para confirmar uma } \\
\text { ideia; usa um tom de voz particular para realçar } \\
\text { certas partes do enunciado. }\end{array}$ \\
\hline $\begin{array}{l}4 \text { Compartilhando } \\
\text { significados }\end{array}$ & $\begin{array}{l}\text { Tornar os significados disponíveis } \\
\text { para todos os estudantes da classe }\end{array}$ & $\begin{array}{l}\text { Repete a ideia de um estudante para toda a } \\
\text { classe; pede a um estudante que repita um } \\
\text { enunciado para toda a classe; compartilha } \\
\text { resultados dos diferentes grupos com toda a } \\
\text { classe; pede aos estudantes que organizem } \\
\text { suas ideias ou dados de experimentos para } \\
\text { relatarem para toda a classe. }\end{array}$ \\
\hline $\begin{array}{l}5 \text { Checando o } \\
\text { entendimento dos } \\
\text { estudantes }\end{array}$ & $\begin{array}{l}\text { Verificar que significados os } \\
\text { estudantes estão atribuindo em } \\
\text { situações específicas. }\end{array}$ & $\begin{array}{l}\text { Pede a um estudante que explique melhor sua } \\
\text { ideia; solicita aos estudantes que escrevam suas } \\
\text { explicações; verifica se há consenso da classe } \\
\text { sobre determinados significados. }\end{array}$ \\
\hline $\begin{array}{l}6 \text { Revendo o } \\
\text { progresso da } \\
\text { estória científica }\end{array}$ & Recapitular e antecipar significados & $\begin{array}{l}\text { Sintetiza os resultados de um experimento } \\
\text { particular; recapitula as atividades de uma aula } \\
\text { anterior; revê o progresso no desenvolvimento da } \\
\text { estória científica até então. }\end{array}$ \\
\hline
\end{tabular}

\section{Resultados e discussão}

Considerando as restrições de espaço para o texto, neste trabalho, faremos uma ilustração da análise feita para as aulas das três professoras, apresentando o quadro de atividades (Quadro 5) relativo a uma aula da professora P2 e parte da discussão feita para um trecho do episódio 2.2 extraído dessa aula. Em seguida, apresentaremos uma sistematização mais completa da análise, com a caracterização das estratégias utilizadas pelas professoras nos episódios selecionados, a partir das quais foi feita uma discussão sobre as dificuldades e possibilidades encontradas nesse processo para a efetivação da Educação Ambiental Crítica.

$\mathrm{Na}$ aula 2, a professora P2 tinha a proposta de trabalhar o tema "Ação humana nos ecossistemas", do capítulo 4 (unidade 1), seguindo a orientação do livro didático adotado, utilizando a estratégia de exposição oral feita pelos alunos da temática selecionada.

\footnotetext{
${ }^{3}$ Relativo aos padrões de interação que emergem à medida que professor e alunos alternam turnos de fala na sala de aula. I-R-A - Iniciação do professor, Resposta do aluno, Avaliação do professor (MORTIMER; SCOTT, 2002).
} 
Ensino de Ciências e Educação Ambiental ...

Quadro 5. Mapa de atividades da $3^{\mathrm{a}}$ aula da professora P2, ministrada no dia 08/05/08.

\begin{tabular}{|l|l|l|l|l|}
\hline Tempo (min.) & Atividade desenvolvida & \multicolumn{1}{|c|}{ Principais temas } & \multicolumn{1}{|c|}{$\begin{array}{c}\text { Ações dos } \\
\text { participantes }\end{array}$} & \multicolumn{1}{c|}{ Comentários } \\
\hline 8 min. & $\begin{array}{l}\text { Exposição oral } \\
\text { Revisão da aula anterior }\end{array}$ & O planeta Terra & $\begin{array}{l}\text { A professora explica a } \\
\text { dinâmica da } \\
\text { apresentação. }\end{array}$ & $\begin{array}{l}\text { Os alunos se } \\
\text { mostram tensos no } \\
\text { início da aula. }\end{array}$ \\
\hline 35 min. & $\begin{array}{l}\text { Exposição oral: Introdução } \\
\text { do tema pela professora. } \\
\text { Apresentação das } \\
\text { produções dos alunos }\end{array}$ & $\begin{array}{l}\text { Ações do homem nos } \\
\text { Ecossistemas: } \\
\text { Desmatamentos } \\
\text { Queimadas, (Poluição } \\
\text { pelas indústrias, } \\
\text { esgotos e lixo). }\end{array}$ & $\begin{array}{l}\text { Os grupos de alunos } \\
\text { constituídos na aula } \\
\text { anterior fazem as } \\
\text { exposições. }\end{array}$ & $\begin{array}{l}\text { Não há interação } \\
\text { entre os diferentes } \\
\text { grupos. }\end{array}$ \\
\hline 13 min. & $\begin{array}{l}\text { Exposição oral } \\
\text { EPISóDIOS (2.1, 2.2) }\end{array}$ & $\begin{array}{l}\text { Alternativas para } \\
\text { minimizar a } \\
\text { problemática ambiental. }\end{array}$ & $\begin{array}{l}\text { A professora faz a } \\
\text { exposição. Os alunos } \\
\text { prestam atenção. }\end{array}$ & $\begin{array}{l}\text { Há pouca interação } \\
\text { dos alunos com a } \\
\text { professora. }\end{array}$ \\
\hline & Finalização da aula & \multicolumn{2}{|l}{} \\
\hline
\end{tabular}

Apresentamos, como ilustração da análise, o episódio 2.2 da aula da professora P2, em que a estratégia utilizada é a apresentação oral do conteúdo pelos alunos com o apoio de um cartaz constituído por figuras relacionadas à temática apresentada.

O referido episódio foi retirado do momento da aula em que um dos alunos do grupo faz uma análise de três das figuras presentes e discute alternativa para o problema do desmatamento.

No turno 1 do episódio 2.2, o aluno, utilizando-se das figuras que constituem o cartaz produzido pelo grupo, estabelece uma comparação entre um ambiente natural sem alteração humana e outro marcado pela presença humana. É importante salientar que, ao fazer a comparação, o aluno consegue perceber a existência de inter-relações entre sociedade e natureza, ainda que de forma superficial. Nessa inter-relação, "a presença do homem no ambiente aparece como um agente que pertence a uma teia de relações da vida social, natural e cultural e interage com ela" (CARVALHO, 2006, p. 37). O aluno dá pistas disso ao se referir às imagens, colocando duas posturas distintas da ação humana: "... aqui ele está desmatando a floresta. Já aqui ele fez. oplantio de trigo, com sua sabedoria." (turno 1). Apesar do uso do termo "sabedoria", ao qual se pode atribuir um sentido religioso, na fala do aluno fica implícito um entendimento sobre a relação sociedade-natureza que deve ser construída, da melhor forma possível, a partir de benefícios e cuidados mútuos.

Por outro lado, a expressão "para que ele ganhe muito dinheiro", utilizada pela mesma aluna ao referir que o homem tem sabedoria para manter um equilíbrio na relação entre sociedade e natureza (turno 1), nos leva a refletir sobre as possibilidades que esse momento representa para uma reflexão junto a toda a classe sobre a díade capital-destruição do ambiente e sobre os reflexos do consumismo. Esse direcionamento é de fundamental importância para o estabelecimento de uma postura crítica e na formação de indivíduos responsáveis pelo mundo em que vivem. 
Episódio 2.2: Discutindo alternativas para o problema do desmatamento.

1. Grupo 6.: "A4 Eu vou falar pra vocês sobre três figuras muito importantes no dia de hoje. Como nós podemos ver, aqui nós temos a primeira figura ((aponta para a figura)), uma lavoura de trigo, esse trigo é muito importante para as nossas vidas, mas aqui é muito diferente do primeiro quadro (laponta para a segunda figura)) aqui ele está desmatando a floresta. Já aqui ele fezo o plantio de trigo, com sua sabedoria, por que assim... nós podemos pensar assim... pra que ele destruiu a mata, as árvores da floresta pra fazer esse plantio de trigo? Por que já veio a sabedoria na consciência dele, pra ele desmatar a árvore e fažer o plantio de trigo... Para que ele ganbe muito dinheiro e tenha sua vida. Aqui ((aponta para a segunda figura)) nós podemos ver o gado, o boi e umas partes da floresta [...]."

2. "Profa.: [...] Fechando o nosso trabalho, ou seja, a ação humana no ecossistema, vocês colocaram tudo isso, o inicio...o verde...o homem luta pra preservar? Luta gente!! ((nesse momento ela se refere às ONGs e pesquisas em favor da preservação)). Depois da extinção ((aponta para os cartazes)) vocês falaram da queimada e comentaram do prejuízo que trazpara o solo, o lixo, o acúmulo de lixo vai prejudicar o solo e até a água que está subterrânea, por que ele atinge os lencóis freáticos [...]. O homem tem como fazer sem precisar destruir tudo isso. Esses lixões, acúmulo de lixo, de uma cidade, lixo de hospital. Não há o acúmulo? E aî? Não tem como as autoridades...? Tem sim como evitar aquele lixo parado nos lixões. Perturbar e prejudicar comunidades inteiras, não é? Então o homem tem como evitar isso. Só que é mais cômodo pra ele... É descobrir que a pista ((referindo-se à rodovia próxima à cidade))... Como não mora ninguém junto..., vamos jogar esse lixo aqui. Mas não é assim. Quando não prejudica os demais que estão próximos, vai prejudicar o solo, vai contaminar a água que está lá debaixo da terra, que você acha que não é contaminada. [...] você veja a ignorância do homem ((se referindo aos esgotos que são lançados nos rios)). Só faltou colocar aqui o uso dos agrotóxicos, os inseticidas, os adubos [...]. Se a gente preparar o ser humano para ficar consciente ou se conscientizar do que acontece com a natureza teremos um mundo melhor."

Diante disso, ressaltamos a importância da estratégia didática adotada (pesquisa e trabalho em grupo com apresentação de resultados), haja vista possibilitar o envolvimento do aluno nas ideias científicas, desde a pesquisa, o estudo em grupo até a socialização de ideias, constituindo um processo de sensibilização, importante e necessário para a significação e suporte na internalização dos conceitos. Todavia, é importante ressaltar que o mediador tem um importante papel nesse processo.

No turno 2, a professora levanta um aspecto importante para a efetiva implantação da Educação Ambiental, que é o fato de se considerarem aspectos de causa e efeito na abordagem da temática lixo. Esses aspectos, quando associados aos fenômenos naturais e às ações humanas, podem possibilitar a formação consistente de uma consciência sobre os problemas. Para isso, a professora faz uma exposição oral, que se fosse seguida de interações com os alunos poderia criar oportunidades concretas para a aprendizagem em diferentes dimensões.

No que se refere à abordagem comunicativa, o episódio 2.2 reflete a dinâmica que vinha sendo anteriormente estabelecida na atividade, pode ser identificada uma abordagem não-interativa/dialógica. No caso do aluno, apesar de ele estar à frente da ação comunicativa, na sua fala, são considerados dois pontos de vistas, o do livro, cujo texto o aluno tomou por base, e o ponto de vista do próprio aluno, que se colocou de forma clara. No turno 2, somente 
a professora produz o enunciado, mas nele ela busca incluir algumas colocações feitas pelos alunos nas suas apresentações, sendo mais de um ponto de vista considerado na ação comunicativa. Ao propor uma atividade de apresentação dos trabalhos, a professora parece ter a intenção de explorar as ideias dos alunos e, também, de desenvolver neles habilidades que vão além da discussão dos conteúdos escolares. Com isso, ela possibilita espaços para que os alunos possam argumentar, discutir e produzir o material de apoio para uma aprendizagem mais ampla. Nessa dinâmica, a professora P2 apresenta uma abordagem ao conteúdo que é conceitual e, também, procedimental. A intenção da professora de introduzir e desenvolver as ideias científicas aparece no turno 2 , quando é abordada, predominantemente, uma perspectiva conceitual (considerando a construção de concepções sobre a relação do homem e ambiente). Ainda nesse turno, a intenção da professora é dar suporte ao processo de internalização das ideias, apresentando uma sistematização das mesmas. Nesse sentido, consideramos que a intervenção da professora teve o objetivo de compartilhar significados.

Essa forma de análise, ilustrada para o episódio 2.2, foi feita para todos os episódios envolvendo as aulas das três professoras. Ao final, fizemos uma síntese da análise estruturada em quadros, a partir dos quais buscamos estabelecer relações entre as categorias usadas no intuito de se caracterizarem as estratégias usadas pelas professoras, como mostraremos nos três quadros a seguir.

\section{Caracterização das estratégias das três professoras nos episódios analisados}

Nos quadros 6, 7 e 8, apresentaremos a caracterização das estratégias utilizadas por cada uma das professoras, P1, P2 e P3. Neles enfatizamos as estratégias e os aspectos discursivos presentes.

Mediante a análise dos quadros 6,7 e 8, em que estão sistematizadas as estratégias didáticas utilizadas e os aspectos discursivos privilegiados pelas professoras investigadas, podemos perceber que as estratégias usadas por P1 (Quadro 6) deixam refletir uma concepção naturalista do ambiente, que toma por base a percepção da natureza como fenômeno estritamente biológico, na qual as interações ecossistêmicas seguem de maneira autônoma e independente da interação com o mundo cultural humano (CARVALHO, 2006), e que os aspectos discursivos não possibilitam uma maior valorização das ideias dos alunos na construção dos significados, haja vista a abordagem comunicativa predominantemente de autoridade e as intervenções serem feitas somente no sentido de reforçar o ponto de vista da ciência escolar, não possibilitando espaço para uma abordagem ao conteúdo numa perspectiva diferente da conceitual, como evidenciado na análise.

Para P2, as estratégias utilizadas (Quadro 7), apesar de conduzidas numa concepção naturalista, parecem possibilitar que sejam considerados mais de um ponto de vista no processo educativo, haja vista a predominância da abordagem comunicativa dialógica e uma maior participação dos alunos no processo, considerando que os episódios foram marcados quase que exclusivamente pela estratégia de exposição oral dos grupos. Por outro lado, a predominância da abordagem não interativa nos possibilita uma reflexão sobre quanto a concepção naturalista da professora se configura como uma dificuldade para o desenvolvimento de um processo educativo que contribua para a formação de valores necessários a uma postura crítica frente às problemáticas ambientais. Isso é percebido nas intervenções que parecem ser 
Cavalcanti Neto, A. L. G.; Amaral, E. M. R.

Quadro 6. Caracterização das estratégias didáticas utilizadas por P1.

\begin{tabular}{|l|l|l|l|}
\hline \multicolumn{1}{|c|}{ Estratégia } & \multicolumn{2}{|c|}{ Espectos discursivos predominantes } \\
\hline \multicolumn{3}{|c|}{ Leitura } & \multicolumn{1}{c|}{ Questionamento } \\
\hline $\begin{array}{l}\text { Intenções } \\
\text { do professor }\end{array}$ & $\begin{array}{l}\text { Guiar os alunos com as ideias } \\
\text { científicas, dando suporte ao } \\
\text { processo de aprendizagem } \\
\text { Introduzir e desenvolver a } \\
\text { estória científica } \\
\text { Possibilitar discussão }\end{array}$ & $\begin{array}{l}\text { Introduzir e desenvolver } \\
\text { a estória científica }\end{array}$ & $\begin{array}{l}\text { Explorar as ideias dos alunos } \\
\text { Guiar os alunos com as ideias } \\
\text { científicas } \\
\text { Introduzir e desenvolver a } \\
\text { estória científica }\end{array}$ \\
\hline $\begin{array}{l}\text { Abordagsibitar discussão } \\
\text { ao conteúdo }\end{array}$ & $\begin{array}{l}\text { Conceitual } \\
\text { Poscus discussão }\end{array}$ & Conceitual \\
\hline $\begin{array}{l}\text { Abordagem } \\
\text { comunicativa }\end{array}$ & $\begin{array}{l}\text { Não interativa/de autoridade } \\
\text { Interativa/de autoridade }\end{array}$ & $\begin{array}{l}\text { Não interativa/de } \\
\text { autoridade }\end{array}$ & $\begin{array}{l}\text { Interativa/dialógica Interativa/de } \\
\text { autoridade } \\
\text { Não interativa/de autoridade }\end{array}$ \\
\hline $\begin{array}{l}\text { Intervenção } \\
\text { do professor }\end{array}$ & $\begin{array}{l}\text { Seleciona significados } \\
\text { Marca significados-chave } \\
\text { Compartilha significados } \\
\text { Dá forma aos significados }\end{array}$ & Marca significados-chave & $\begin{array}{l}\text { Dá forma aos significados } \\
\text { Marca significados-chave }\end{array}$ \\
\hline
\end{tabular}

Quadro 7. Caracterização das estratégias didáticas utilizadas por P2.

\begin{tabular}{|c|c|c|}
\hline Estratégia & Exposição oral & Apresentação oral dos grupos \\
\hline \multicolumn{3}{|c|}{ Aspectos discursivos predominantes } \\
\hline $\begin{array}{l}\text { Intenções } \\
\text { do professor }\end{array}$ & $\begin{array}{l}\text { Introduzir e desenvolver as ideias científicas } \\
\text { Dar suporte ao processo de internalização }\end{array}$ & $\begin{array}{l}\text { Explorar as ideias dos alunos e desenvolver } \\
\text { neles habilidades que vão além da discussão } \\
\text { dos conteúdos escolares }\end{array}$ \\
\hline $\begin{array}{l}\text { Abordagem } \\
\text { ao conteúdo }\end{array}$ & Conceitual & $\begin{array}{l}\text { Conceitual } \\
\text { Procedimental }\end{array}$ \\
\hline $\begin{array}{l}\text { Abordagem } \\
\text { comunicativa }\end{array}$ & $\begin{array}{l}\text { Não interativa/de autoridade } \\
\text { Não interativa/dialógica }\end{array}$ & $\begin{array}{l}\text { Interativa/dialógica } \\
\text { Não interativa/dialógica }\end{array}$ \\
\hline $\begin{array}{l}\text { Intervenção } \\
\text { do professor }\end{array}$ & $\begin{array}{l}\text { Rever o progresso da estória científica } \\
\text { Seleciona significados } \\
\text { Compartilha significados }\end{array}$ & Compartilha significados \\
\hline
\end{tabular}

feitas para reforçarem a concepção naturalista da relação sociedade-natureza, sendo a abordagem ao conteúdo direcionada à perspectiva conceitual e procedimental.

Em relação a P3 (Quadro 8), as estratégias didáticas utilizadas pela professora nos possibilitam estabelecer uma relação entre a concepção socioambiental apresentada pela professora, concepção essa que orienta-se por uma racionalidade complexa e interdisciplinar e pensa o ambiente não como sinônimo de natureza intocada, mas como um campo de intera- 
Ensino de Ciências e Educação Ambiental ...

Quadro 8. Caracterização das estratégias didáticas utilizadas por P3.

\begin{tabular}{|c|c|c|c|}
\hline Estratégia & Questionamento & Orientar a realização de uma tarefa & Exibição de vídeo \\
\hline \multicolumn{4}{|c|}{ Aspectos discursivos predominantes } \\
\hline $\begin{array}{l}\text { Intenções } \\
\text { do professor }\end{array}$ & $\begin{array}{l}\text { Guiar os alunos para elaboração do } \\
\text { trabalho; } \\
\text { Refletir sobre as questões } \\
\text { ambientais e sobre o compromisso } \\
\text { social de cada um com relação às } \\
\text { mesmas. } \\
\text { Possibilitar a condição, aos alunos, } \\
\text { de tomarem decisões } \\
\text { fundamentadas e críticas. } \\
\text { Guiar os alunos na discussão sobre } \\
\text { questões ambientais e compromisso } \\
\text { social }\end{array}$ & $\begin{array}{l}\text { Guiar os alunos no processo de } \\
\text { elaboração do plano de ação }\end{array}$ & $\begin{array}{l}\text { Guiar os alunos no } \\
\text { trabalho } \\
\text { Dar suporte ao } \\
\text { processo de } \\
\text { internalização }\end{array}$ \\
\hline $\begin{array}{l}\text { Abordagem } \\
\text { ao conteúdo }\end{array}$ & $\begin{array}{l}\text { Conceitual } \\
\text { Atitudinal }\end{array}$ & $\begin{array}{l}\text { Conceitual } \\
\text { Atitudinal }\end{array}$ & Conceitual \\
\hline $\begin{array}{l}\text { Abordagem } \\
\text { comunicativa }\end{array}$ & $\begin{array}{l}\text { Interativa/Dialógica } \\
\text { Interativa/de autoridade }\end{array}$ & $\begin{array}{l}\text { Interativa/dialógica } \\
\text { Interativa/de autoridade }\end{array}$ & \\
\hline $\begin{array}{l}\text { Intervenção } \\
\text { do professor }\end{array}$ & $\begin{array}{l}\text { Dá forma aos significados } \\
\text { Marca significados-chave } \\
\text { Compartilha significados } \\
\text { Checa o entendimento dos } \\
\text { estudantes }\end{array}$ & $\begin{array}{l}\text { Dá forma aos significados } \\
\text { Compartilha significados } \\
\text { Marca significados-chave }\end{array}$ & \\
\hline
\end{tabular}

\begin{tabular}{|c|c|c|c|c|}
\hline Estratégia & Análise do vídeo & Investigação & Exposição oral & $\begin{array}{c}\text { Apresentação e } \\
\text { discussão dos dados }\end{array}$ \\
\hline \multicolumn{5}{|c|}{ Aspectos discursivos predominantes } \\
\hline $\begin{array}{l}\text { Intenções } \\
\text { do professor }\end{array}$ & $\begin{array}{l}\text { Checar as ideias dos } \\
\text { alunos }\end{array}$ & $\begin{array}{l}\text { Checar as ideias dos } \\
\text { alunos }\end{array}$ & $\begin{array}{l}\text { Guiar os alunos } \\
\text { com as ideias }\end{array}$ & $\begin{array}{l}\text { Guiar os alunos com as } \\
\text { ideias científicas } \\
\text { Checar as ideias dos } \\
\text { alunos }\end{array}$ \\
\hline $\begin{array}{l}\text { Abordagem } \\
\text { ao conteúdo }\end{array}$ & $\begin{array}{l}\text { Conceitual } \\
\text { Atitudinal }\end{array}$ & Conceitual & Atitudinal & $\begin{array}{l}\text { Conceitual } \\
\text { Atitudinal }\end{array}$ \\
\hline $\begin{array}{l}\text { Abordagem } \\
\text { comunicativa }\end{array}$ & $\begin{array}{l}\text { Interativa/Dialógica } \\
\text { Interativa/de autoridade }\end{array}$ & $\begin{array}{l}\text { Não interativa/ } \\
\text { dialógica }\end{array}$ & $\begin{array}{l}\text { Interativa/de } \\
\text { autoridade }\end{array}$ & $\begin{array}{l}\text { Interativa/Dialógica } \\
\text { Interativa/de autoridade }\end{array}$ \\
\hline $\begin{array}{l}\text { Intervenção } \\
\text { do professor }\end{array}$ & $\begin{array}{l}\text { Compartilha significados } \\
\text { Checa o entendimento } \\
\text { dos estudantes }\end{array}$ & $\begin{array}{l}\text { Dá forma aos } \\
\text { significados }\end{array}$ & $\begin{array}{l}\text { Dá forma aos } \\
\text { significados } \\
\text { Marca } \\
\text { significados- chave }\end{array}$ & $\begin{array}{l}\text { Compartilha significados } \\
\text { Dá forma aos } \\
\text { significados }\end{array}$ \\
\hline
\end{tabular}

ções entre a cultura, a sociedade e a base física/biológica dos processos vitais, no qual todos os elementos dessa relação se modificam dinâmica e mutuamente (CARVALHO, 2006). Tal concepção parece direcionar o processo educativo para uma finalidade mais ampla, haja vista as 
intenções evidenciadas no processo de análise. Apesar da possibilidade oferecida pelas estratégias didáticas para abordagem ao conteúdo nas três perspectivas, foram privilegiadas as dimensões conceitual e atitudinal. As intervenções, nesse caso, parecem ser no sentido de promoverem uma maior participação dos alunos e uma valorização de diversos pontos de vista, bem como tomarem decisões fundamentadas e críticas, considerando uma oscilação entre as abordagens interativa/dialógica e interativa/de autoridade em todo processo observado.

\section{Considerações finais}

De acordo com a análise, podemos considerar que a professora $\mathrm{P}$, que adotou estratégias didáticas com maior participação do aluno e apresentava uma visão socioambiental para a relação homem-ambiente, foi mais dialógica, preocupando-se com o conteúdo atitudinal, e possibilitando o diálogo entre os conhecimentos cotidianos e os conhecimentos científicos. No entanto, mesmo diante dessa constatação, não se pode afirmar que tais estratégias didáticas foram escolhidas unicamente devido a esses aspectos, uma vez que esse tipo de postura docente pode emergir, também, por razões relacionadas com a forma pela qual o processo educativo é visto e tratado. Para ampliar a abrangência dessa análise, poderiam ser também considerados os objetivos de ensino dos componentes curriculares envolvidos, uma vez que as duas primeiras professoras, P1 e P2, estavam em aulas de Ciências, enquanto P3 estava responsável por abordar diretamente a Educação Ambiental, como parte de uma reforma educacional do Estado que pretende inserir esta disciplina no Ensino Fundamental. Nesse sentido, seria pertinente buscar entender o compromisso de $\mathrm{P} 3 \mathrm{em}$ termos de currículo ou programa da disciplina ministrada. Todavia, diante dos resultados, nos indagamos sobre a seguinte questão: inserir a disciplina específica no currículo seria a melhor forma de se efetivar a Educação Ambiental no Ensino Fundamental? Para responder a tal questionamento seria interessante, em trabalhos futuros, se analisarem as estratégias didáticas utilizadas pela professora P3 em aulas de Ciências.

Refletindo, ainda, sobre a questão levantada e buscando identificar as possibilidades e dificuldades apresentadas pelas professoras no que diz respeito ao desenvolvimento da Educação Ambiental Crítica em aulas de Ciências e de Educação Ambiental, percebemos que, apesar das dificuldades apresentadas, são muitas as possibilidades do desenvolvimento dessa perspectiva crítica nos dois contextos. Dentre elas podemos destacar: no ensino de ciências e de Educação Ambiental existem espaços didáticos que podem ser utilizados para discussão das questões ambientais nos vários aspectos - biológicos/químicos/físicos, sociais, históricos, culturais e políticos. Tais espaços emergem, dentre outros, de orientações curriculares recentes e da pesquisa educacional, e puderam ser observados em vários momentos na prática das três professoras.

Uma segunda possibilidade está relacionada com o uso de estratégias didáticas que buscam privilegiar o diálogo entre os vários saberes: cotidianos, científicos, culturais, e outros. Um processo educativo que considere essa diversificação destaca-se como importante e necessário para proporcionar uma efetiva participação dos alunos no processo de construção de conceitos, procedimentos e atitudes, o que é objetivado pelos fundamentos da Educação Ambiental Crítica. 
Em relação às dificuldades, na análise apresentada para as três professoras, percebemos em P1 e P2, ao contrário de P3, que a concepção naturalista constitui um dos fatores limitantes para a abordagem das questões ambientais nas suas diferentes dimensões, haja vista a relação homem-natureza ser apresentada como predominantemente negativa durante toda a mediação feita por P1 e P2.

Ainda no que diz respeito às professoras P1 e P2, um dos fatores que, a nosso ver, dificultou o desenvolvimento de aspectos ambientais numa perspectiva crítica está relacionado à concepção que as mesmas apresentaram do processo educativo na formação dos sujeitos. Tal concepção foi percebida pela identificação de aspectos discursivos que evidenciam uma prática docente específica. Para P1, verificamos uma predominância de abordagem dos conteúdos conceituais e de uma abordagem comunicativa de autoridade, que, apesar de importante no processo de construção de significados, quando predominante em relação à abordagem dialógica dificulta o diálogo entre os saberes, fator que se configura como limitante na formação de sujeitos críticos diante das problemáticas ambientais. As intervenções realizadas por P1 durante o desenvolvimento das três estratégias são, predominantemente, no sentido de dar forma ao conteúdo e marcar os conteúdos-chave. Tais intervenções, quando associadas a uma abordagem de autoridade, dificultam o direcionamento do processo educativo para uma finalidade mais ampla. Com relação a P2, apesar da adoção de uma abordagem comunicativa dialógica e das evidências da intenção de compartilhar significados, nas intervenções feitas pela professora, houve a predominância da abordagem não interativa no episódio como um todo. Isso parece se configurar como uma limitação para a abordagem aos conteúdos numa perspectiva que vá além da conceitual e procedimental, dificultando, com isso, o estabelecimento de um processo educativo que busque a formação de valores e atitudes, pressuposto básico para o desenvolvimento de uma postura crítica e participativa com relação às questões ambientais.

Em se tratando de P3, a predominância de aspectos discursivos que possibilitam uma maior participação dos alunos, bem como a busca pela formação de conceitos e atitudes, nos levam a constatar que a referida professora apresenta uma concepção mais ampla do processo educativo. Ainda em relação a $\mathrm{P} 3$, outro aspecto que merece reflexão está relacionado ao tratamento superficial dado aos conceitos científicos. Tal evidência nos permite pensar que, talvez, pelo fato de a professora estar responsável pelo cumprimento de um programa que não prioriza a questão científica - pelo menos, é o que parece ser entendido pelo fato de a nova disciplina não se encontrar vinculada a nenhuma disciplina científica específica já existente. Todavia, vale salientar que esse aspecto se apresenta como uma limitação para o desenvolvimento de uma concepção crítica, uma vez que o conhecimento científico, além de se configurar como um dos saberes que deve estar presente no contexto de uma formação ambiental crítica, o fato de conhecer a Ciência pode ajudar os indivíduos na tomada de decisões, contribuindo para que as transformações que promovam sejam tecnicamente embasadas.

Nesse contexto, diante das possibilidades apresentadas nas aulas analisadas, acreditamos que a inserção da Educação Ambiental Crítica no nível Fundamental é possível, desde que, extrapolando as abordagens feitas no livro didático, valorize o diálogo entre saberes e seja interativa, possibilitando a formação de sujeitos críticos e capazes de encontrar respostas para as problemáticas socioambientais atuais. Além disso, a análise mostra que é necessário pensar sobre a inclusão da visão crítica para a Educação Ambiental, também, na formação continuada de professores, de forma a prover reflexões, sobretudo, com relação às concepções docentes sobre este tema. 
Cavalcanti Neto, A. L. G.; Amaral, E. M. R.

\section{Referências}

AMARAL, E. M. R.; MORTIMER, E. F. Uma metodologia para análise da dinâmica entre zonas de um perfil conceitual no discurso da sala de aula. In: SANTOS, F. M. T.; GRECA, I. M. (Orgs.). A pesquisa em ensino de ciências no Brasil e suas metodologias. Ijuí: Ed. Unijuí, 2007. p. 239-296.

BRASIL. Ministério da Educação. Secretaria de Educação Média e Tecnológica.

Orientações curriculares do ensino médio: ciências da natureza, matemática e suas tecnologias. Brasília: MEC/SEB, 2004.

. Ministério da Educação. Secretaria de Educação Fundamental. Parâmetros

Curriculares Nacionais: ciências naturais. Brasília, 1998a.

. Ministério da Educação. Secretaria de Educação Fundamental. Parâmetros

Curriculares Nacionais: temas transversais. Brasília, 1998b.

Ministério da Educação. Secretaria de Educação Fundamental. Parâmetros

Curriculares Nacionais - introdução. Brasília, 1997.

CACHAPUZ, A. F.; PRAIA, J. F.; JORGE, M. P. Ciências, educação em ciências e ensino de ciências. Lisboa: Ministério de Educação, 2002.

CARVALHO, I. C. M. Educação ambiental: a formação do sujeito ecológico. 2. ed. São Paulo: Cortez, 2006.

CHASSOT, A. Alfabetização científica: questões e desafios para a educação. Ijuí: Ed. Unijuí, 2006.

DIAS, G. F. Atividades interdisciplinares de educação ambiental. São Paulo: Global/ Gaia, 1999.

GUIMARÃES, M. A dimensão ambiental na educação. 7. ed. Campinas: Papirus, 2005.

HAYDT, R. C. C. Curso de didática geral. 6. ed. São Paulo: Ática, 1999.

JACOBI, P. R. Educação ambiental: o desafio da construção de um pensamento crítico, complexo e reflexivo. Educação e Pesquisa, São Paulo, v. 31, n. 2, p. 233-250, 2005.

LOUREIRO, C. F. B. Trajetória e fundamentos da educação ambiental. 2. ed. São Paulo: Cortez, 2006.

MASETTO, M. T. Didática: a aula como centro. 4. ed. São Paulo: FTD, 1997.

MERGULHÃO, M. C. Zoológico: uma sala de aula viva. 1998. 143f Dissertação (Mestrado em Educação) - Faculdade de Educação, Universidade de São Paulo, São Paulo, 1998.

MORIN, E. Os sete saberes necessários à educação do futuro. 8. ed. São Paulo: Cortez, 2003.

MORTIMER, E. F.; SCOTT, P. H. Atividade discursiva nas salas de aula de ciências: uma ferramenta sociocultural para analisar e planejar o ensino. Investigações em Ensino de Ciências, Porto Alegre, v. 7, n. 3, p. 283-306, 2002.

Artigo recebido em novembro de 2010 e aceito em fevereiro de 2011. 